\title{
Characterization of Streptococcus suis capsular type 2 haemolysin
}

\author{
Marcelo G. Gottschalk, Sonia Lacouture and J. Daniel Dubreuil
}

Author for correspondence: Marcelo Gottschalk. Tel: +1 514773 8521, ext. 374. Fax : +1 5147735633.

Groupe de Recherche sur les Maladies Infectieuses du Porc (GREMIP), Faculté de médecine vétérinaire, Université de Montréal, C.P. 5000, St-Hyacinthe, Québec J2S 7C6, Canada

\begin{abstract}
The production of a haemolysin by Streptococcus suis capsular type 2 was investigated. Human group 0 erythrocytes were the most susceptible, followed by horse, sheep, cow and pig red blood cells, which exhibited similar susceptibilities; rabbit erythrocytes were the least susceptible. The haemolysin was produced at the end of the exponential growth phase. The toxin described in this paper was purified by affinity chromatography using a thiopropylSepharose 6B column. It is an extracellular protein with a molecular mass of $65 \mathrm{kDa}$. The haemolysin belongs to the family of toxins known as antigenically related cholesterol-binding cytolytic toxins, since it shares common characteristics with other members of this family, such as sensitivity to oxygen and oxidizing agents, activation by reducing agents, inhibition by low concentrations of cholesterol, formation of transmembrane pores and a 'multihit' mechanism of action. In addition, anti-streptolysin antibodies inhibited the haemolytic activity caused by the $S$. suis haemolysin. Antibodies against the haemolysin could not be detected in pigs experimentally infected with a haemolytic positive strain of S. suis capsular type 2. To our knowledge, this is the only Lancefield group D Streptococcus producing a haemolysin with these characteristics. The role of this haemolysin in the pathogenesis of $S$. suis infections remains to be investigated.
\end{abstract}

Keywords: Streptococcus suis, haemolysin

\section{INTRODUCTION}

Streptococcus suis capsular type 2 is an important swine pathogen responsible for a variety of infections such as septicaemia, meningitis, arthritis, endocarditis and pneumonia (Higgins et al., 1992). It may also be the cause of serious infections in man, with various degrees of complication (Arends \& Zanen, 1988). So far, 29 capsular types have been described and capsular type 2 is more frequently isolated from diseased pigs than any other capsular type (Gottschalk et al., 1989, 1991a). Pathogenesis of these infections is still unclear and different bacterial components, such as capsular polysaccharides and some cell wall proteins, have been reported as virulence factors (Vecht et al., 1992; Gottschalk et al., 1992). It has been shown that $S$. suis capsular type 2 isolates recovered from diseased animals possess a larger amount of capsular material than those recovered from nasal cavities or tonsils of clinically healthy animals (Gottschalk et al., 1991b); in addition, studies using intra-

Abbreviations: EF, extracellular factor; HU, haemolytic units; MRP, muramidase release protein; RBC, red blood cells. peritoneal chambers have shown that virulent strains possess a thicker capsule than non-virulent strains (Quessy et al., 1994). Finally, a non-capsulated mutant obtained from a highly virulent strain was demonstrated to be totally avirulent (Gottschalk et al., 1992).

Vecht and co-workers have recently reported that two proteins were detectable only in virulent strains of $S$. suis capsular type 2 (Vecht $e t$ al., 1992, 1993). The first protein, which is known as muramidase release protein (MRP), is a cell-wall-associated protein. The second one, called extracellular factor (EF), is an extracellular protein. Three different phenotypes were recognized with these proteins: $\mathrm{MRP}^{+} \mathrm{EF}^{+}, \mathrm{MRP}^{+} \mathrm{EF}^{-}$and $\mathrm{MRP}^{-} \mathrm{EF}^{-}$. Most isolates from diseased pigs were $\mathrm{MRP}^{+} \mathrm{EF}^{+}$, whereas most human isolates were $\mathrm{MRP}^{+} \mathrm{EF}^{-}$(Vecht et al., 1992). However, when culture supernatants of $\mathrm{MRP}^{+} \mathrm{EF}^{-}$strains were tested by immunoblotting using specific monoclonal antibodies raised against $\mathrm{EF}$, related proteins of variable size $\left(\mathrm{EF}^{*}\right)$ and with a higher molecular mass were recognized (Vecht $e t$ al., 1993). More recently, Quessy et al. (1993) described a new phenotype, $\mathrm{MRP}^{-} \mathrm{EF}^{+}$.

Different streptococci groups produce haemolysins which 
have been shown to be involved in the pathogenesis of infection. For example, Lancefield group A S. pyogenes, Lancefield group B streptococci, Lancefield group C streptococci, Lancefield group $G$ streptococci and $S$. pneumoniae (Alouf, 1980; Tapsall \& Phillips, 1991; Alouf \& Geoffroy, 1991). S. suis is known to be $\alpha$-haemolytic on blood agar plates; however, some authors have reported that $\beta$-haemolysis can be observed with some strains, especially when cultured on horse blood agar (Estoepangestie \& Lämmler, 1993; Hommez et al., 1986). Lee et al. (1984), who studied cross-reactivities between non-groupable streptococci and pneumococcal group 19 polysaccharides, reported that the reference strain of $S$. suis capsular type 8 produces a lysin which is different from that of $S$. pneumoniae. Jacobs et al. (1994) have recently reported the presence in some strains of $S$. suis of a thiol-activated haemolysin, based on its inhibition by cholesterol. The aim of this study was to characterize a haemolysin produced by $S$. suis capsular type 2 .

\section{METHODS}

Bacterial strains and growth conditions. The reference strain of $S$. suis capsular type 2 (S735) was obtained from Dr J. Henrichsen, Pneumococcus Department, Statens Seruminstitut, Denmark. A S. pneumoniae serotype 5 (Ambrose) strain, also provided by Dr J. Henrichsen, was used as a positive control. Inoculum was prepared by inoculating two to three colonies from a blood-agar plate into $5 \mathrm{ml}$ Todd-Hewitt broth (THB; Difco). After $18 \mathrm{~h}$ incubation, $0.5 \mathrm{ml}$ of this culture was used to inoculate $50 \mathrm{ml}$ fresh, pre-warmed THB. Culture samples were taken at different times of incubation and haemolysin activity was evaluated as described later. The number of colony-forming units (c.f.u.) was calculated by viable cell count. Occasionally, shaking cultures were assayed. The bacterial sediment obtained after centrifugation was washed twice, sonicate five times for 30 s each (Vibra Cell; Sonics and Materials) and also tested for haemolytic activity.

Haemolysin assay. The haemolysin assay was performed by preparing twofold dilutions (from $1: 2$ to $1: 256$ ) of the supernatant in a solution of $0.145 \mathrm{M} \mathrm{NaCl}$ and $7 \mathrm{mM} \mathrm{Na}_{2} \mathrm{HPO}_{4}$, $\mathrm{pH} 7 \cdot 2$. An equal amount of horse red blood cells (RBC), washed twice in the solution mentioned above, was added to $0.5 \mathrm{ml}$ of each dilution (final concentration of RBC: $1.4 \%$ ). Following incubation for $1 \mathrm{~h}$ at $37^{\circ} \mathrm{C}$, the mixtures were sedimented by centrifugation $(1500 \mathrm{~g}$ for $10 \mathrm{~min}$ ) and supernatants transferred to polystyrene microplates (Dynatech). Following corrections for controls, which lacked either haemolysin preparation or erythrocytes, the $\mathrm{OD}_{540}$ of the supernatant fluid of each dilution was read on a spectrophotometer (Titertek Multiskan, Flow Laboratories). To study the kinetics of haemolysin-induced erythrocyte lysis at different temperatures, experiments were performed essentially as described above and samples of the haemolysin-erythrocyte suspension were obtained at different time intervals.

A standard curve of haemolysis was obtained using a methodology previously described (Palmer, 1981). The reciprocal of the highest dilution of a given cell-free supernatant fluid sample that exhibited at least $50 \%$ of RBC lysis was taken as the titre, in haemolytic units (HU), of the haemolysin in that sample. Occasionally, the activity was also recorded as direct spectrophotometric readings of a 1:32 dilution of the supernatant. Values expressed in Results are the mean of at least three independent assays. In addition to horse $\mathrm{RBC}$, the activity of the haemolysin was also determined on RBC from pig, rabbit, sheep, cow and human (group O). The haemolysin test was performed as described above.

Effect of different treatments on the haemolytic activity. For the characterization of the haemolysin, supernatants from a $15 \mathrm{~h}$ culture were used. Culture supernatant from the haemolytic positive strain was tested for its haemolytic activity after being heated at $55^{\circ} \mathrm{C}, 58^{\circ} \mathrm{C}$ and $60^{\circ} \mathrm{C}$ for $1 \mathrm{~h}$, and boiled for $30 \mathrm{~min}$. The effect of $\mathrm{pH}$ on the haemolytic activity was tested by modifying the $\mathrm{pH}$ of a saline solution from 3 to 11 by the addition of $\mathrm{HCl}$ or $\mathrm{NaOH}$. The supernatant was also treated for $1 \mathrm{~h}$ at room temperature with $5 \mathrm{mM}$ dithiothreitol (DTT; Sigma) (pH previously adjusted to $7 \cdot 6$ ); with $100 \mu \mathrm{g}$ and $5 \mathrm{mg}$ of ethanol-soluble and water-soluble cholesterol $\mathrm{ml}^{-1}$ respectively, and with $1 \mathrm{mM}$ and $5 \mathrm{mM}$ sodium periodate. The supernatant was also treated with $100 \mu \mathrm{g}$ proteinase $\mathrm{K} \mathrm{ml}^{-1}$ (Sigma), and incubated at $55^{\circ} \mathrm{C}$ for $1 \mathrm{~h}$. In addition, the effect of $\mathrm{CaCl}_{2}$ and $\mathrm{MgCl}_{2}(0.1$ and $0.01 \mathrm{M}), \mathrm{ZnCl}_{2}(0.1$ and $0.05 \mathrm{mM})$ and EGTA $(2.5 \mathrm{mM})$ on the haemolysin was studied. After incubation of the supernatant with each of these compounds for $1 \mathrm{~h}$ at room temperature, haemolytic activity was then evaluated as described above. Finally, the effect of oxygen on haemolytic activity was determined by bubbling oxygen gas at a flow rate of $100 \mathrm{ml}$ $\mathrm{min}^{-1}$ through $5 \mathrm{ml}$ supernatant for $90 \mathrm{~min}$. For all the studies, the haemolytic activity of the treated supernatant was measured and compared with that of a non-treated supernatant which was evaluated at the same time. It has to be noted that, under the above conditions, none of the products used induced erythrocyte lysis.

The haemolysin was tested in inhibition assays using human anti-streptolysin immunoglobulins (WBAG Resources). Twofold dilutions of the IgG were made and incubated for $1 \mathrm{~h}$ at $37^{\circ} \mathrm{C}$ with the supernatant containing the haemolysin. The mixtures were then incubated with RBC and the haemolysis test was performed as described apove. The titre was evaluated as the highest dilution which in hibited $50 \%$ of the haemolytic activity. In addition, the production of antibodies against $S$. suis haemolysin in vivo in infected animals was tested using sera from six pigs experimentally inoculated with the reference strain of $S$. suis capsular type 2 . Six-week-old specific-pathogen-free piglets were inoculated intravenously with a suspension containing $10^{9}$ c.f.u. All animals presented severe clinical signs and they had to be treated with a single dose of antibiotics. Animals received a second challenge with a similar number of c.f.u. one month after the first inoculation. Animals were bled once a week for six weeks (until two weeks after the second inoculation). The inhibition assay was performed as described above.

Osmotic protection of erythrocytes. The protective effect of high molecular mass compounds against lysis of erythrocytes was evaluated using hydrophilic molecules of increasing diameter (Scherrer \& Gerhardt, 1971). The following colloids were tested (molecular diameter in $\mathrm{nm}$ ): xylose $(0 \cdot 62)$, raffinose $(1 \cdot 14)$, polyethylene glycol (PEG) $1450(2 \cdot 40)$, inulin $(2 \cdot 80)$, PEG 3350 (3.80), PEG 8000 (6.40) and PEG 10000 (7.20). The colloids were mixed with $\mathrm{RBC}$ and a 1:32 dilution of the supernatant containing the haemolysin was added. The final concentration of colloids was $30 \mathrm{mM}$, with the exception of inulin and PEG, which were used at $15 \mathrm{mM}$ because of their solubility. The mixtures were incubated at $37^{\circ} \mathrm{C}$ for $60 \mathrm{~min}$ before reading haemolytic activity.

Purification of the haemolysin. As complete media such as THB should be avoided for purification purposes because of the presence of large molecular mass peptides (Alouf, 1980), a beef and yeast extract diffusate medium was used. The medium was 
prepared by dissolving $100 \mathrm{~g}$ beef extract and $100 \mathrm{~g}$ yeast extract (Difco) in 1 litre distilled water by moderate heating $\left(45-50^{\circ} \mathrm{C}\right)$. This concentrate was dialysed against 51 distilled water for $72 \mathrm{~h}$ at $4{ }^{\circ} \mathrm{C}$. The dialysis sacs and contents were discarded and the diffusate was adjusted with distilled water to $25 \mathrm{l}$ and sterilized. Prior to inoculation, $500 \mathrm{ml} 10 \%(\mathrm{w} / \mathrm{v})$ sodium bicarbonate in distilled water and $1 \%(\mathrm{w} / \mathrm{v})$ glucose were added. After $18 \mathrm{~h}$ incubation, the culture was centrifuged for $30 \mathrm{~min}$ at $10000 \mathrm{~g}$, filtered $(0.2 \mu \mathrm{m}$ pore size filters; Millipore $)$ and precipitated with $50 \%(\mathrm{v} / \mathrm{v})\left(\mathrm{NH}_{4}\right)_{2} \mathrm{SO}_{4}$. The precipitate was ultrafiltrated using an Amicon system YM 30 membrane. The unfiltered material $(>30 \mathrm{kDa}$ ) was applied to an affinity column consisting of a thiopropyl-Sepharose 6B column (Pharmacia) at a flow rate of about $6-8 \mathrm{ml} \mathrm{h}^{-1}$. The column was washed with PBS ( $\mathrm{pH} \mathrm{6.8)}$ and eluted with PBS ( $\mathrm{pH} 7 \cdot 5$ ) containing 5 mM DTT. The material was collected in different fractions and monitored for haemolytic activity. The haemolytic fractions were pooled and subjected to SDS-PAGE (20 $\mu$ l loading volume; a total of $15 \mu \mathrm{g}$ protein) in $7.5 \%(\mathrm{w} / \mathrm{v})$ polyacrylamide slab gels as described by Laemmli (1970) and stained using silver nitrate.

\section{RESULTS}

\section{General characteristics of the haemolysin produced by $S$. suis capsular type 2}

The haemolysin was not cell-bound, since the bacterial sediment obtained after centrifugation of cultures (regardless of cultural conditions) did not lyse erythrocytes, even after sonication of bacterial cells. Haemolytic activity was always observed in whole cell culture, culture supernatants and culture filtrates. On the other hand, the positive control ( $S$. pneumoniae, Ambrose strain) gave a positive haemolytic reaction with both supernatant and washed sonicated cells. A lower haemolytic activity was obtained with shaking $(32 \mathrm{HU})$ than with stationary (64 HU) cultures.

The haemolysin of $S$. suis capsular type 2 was produced at the end of the exponential phase of the growth cycle (Fig. 1). Haemolysin production was preceded by a latent period (about $8 \mathrm{~h}$ ) where no haemolytic activity could be detected. Maximum haemolytic activity was observed between 15 and $24 \mathrm{~h}$ incubation. After $24 \mathrm{~h}$ incubation, the haemolysin detected in the supernatant decreased, and almost completely disappeared after $48 \mathrm{~h}$ incubation.

Relatively similar haemolytic kinetics were observed when different temperatures of incubation were used for the haemolytic assay, the highest haemolytic activity being observed at $37^{\circ} \mathrm{C}$ and the lowest at $4{ }^{\circ} \mathrm{C}$. In all cases, erythrocyte lysis was preceded by a pre-lytic phase of approximately $10 \mathrm{~min}$ for the incubation at $37^{\circ} \mathrm{C}$; $15 \mathrm{~min}$ for the incubation at $25^{\circ} \mathrm{C}$; and $20 \mathrm{~min}$ for the incubation at $4^{\circ} \mathrm{C}$. After $120 \mathrm{~min}$, the activity almost levelled off for the three incubation temperatures (Fig. 2).

Human group $\mathrm{O} R B C$ were the erythrocytes most susceptible to the haemolysin; horse, pig, cow, and sheep RBC presented similar susceptibilities whereas rabbit RBC were the most resistant to haemolysis. When various amounts of erythrocytes were incubated with the haemolysin, maximum lysis was observed when a $2 \%(\mathrm{v} / \mathrm{v}) \mathrm{RBC}$ suspension was used (Fig. 3).
Finally, haemolysin activity in the cell-free supernatant disappeared after 1 and $4 \mathrm{~d}$ storage at $37^{\circ} \mathrm{C}$ and $25^{\circ} \mathrm{C}$, respectively; at $4{ }^{\circ} \mathrm{C}$, some activity was still present after $6 \mathrm{~d}$ storage. Activity was conserved better still at $-20^{\circ} \mathrm{C}$. Integral haemolytic activity was observed after at least 1 year of storage at $-70^{\circ} \mathrm{C}$.

\section{Effect of different treatments on haemolytic activity}

Results of the effect of different treatments on haemolytic activity are shown in Table 1 . Temperature affected haemolytic activity. Incubation of the supernatant at $60{ }^{\circ} \mathrm{C}$ for $1 \mathrm{~h}$ or boiling for $30 \mathrm{~min}$ completely abolished haemolytic activity. When the haemolysin was incubated

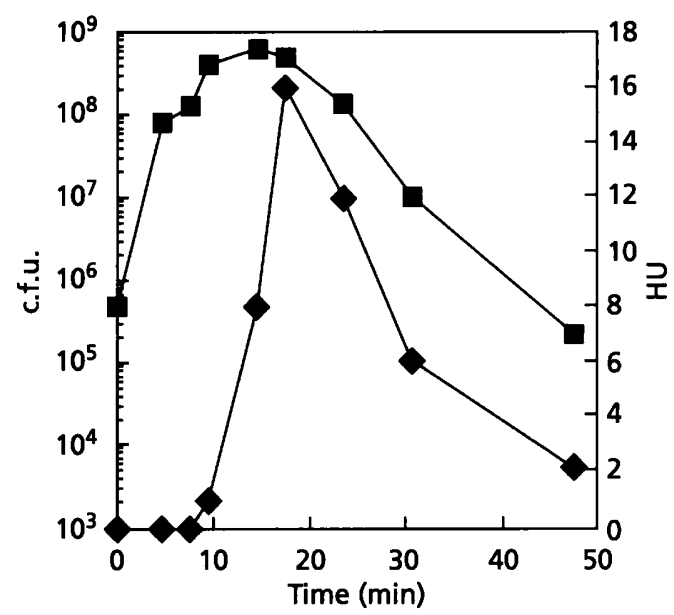

Fig. 1. Bacterial growth and haemolysin production by $S$. suis capsular type 2, strain S735. Bacterial cells were grown in THB and haemolysin assayed using horse RBC. $\square$, Bacterial growth; $\bullet$, haemolytic activity in culture supernatant.

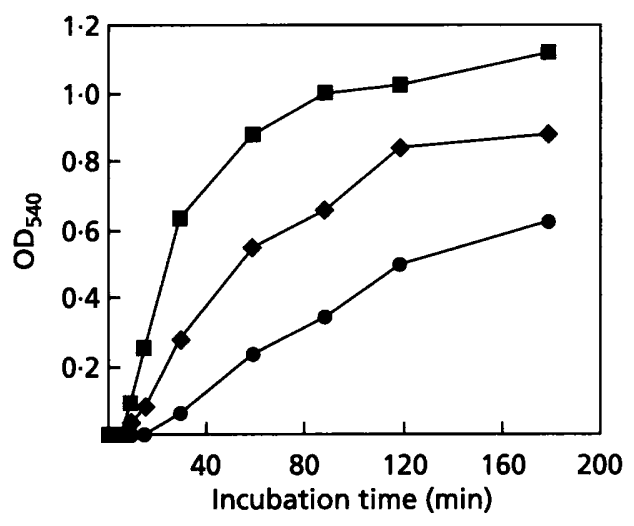

Fig. 2. Kinetics of the haemolytic reaction. Mean $O D_{540}$ corresponds to a 1:32 dilution of the supernatant of $S$. suis capsular type 2, strain \$735. Haemolysin assay was performed using horse RBC. $\square$. Incubation at $37^{\circ} \mathrm{C}$; $\bullet$, incubation at $25^{\circ} \mathrm{C} ; 0$, incubation at $4^{\circ} \mathrm{C}$. 


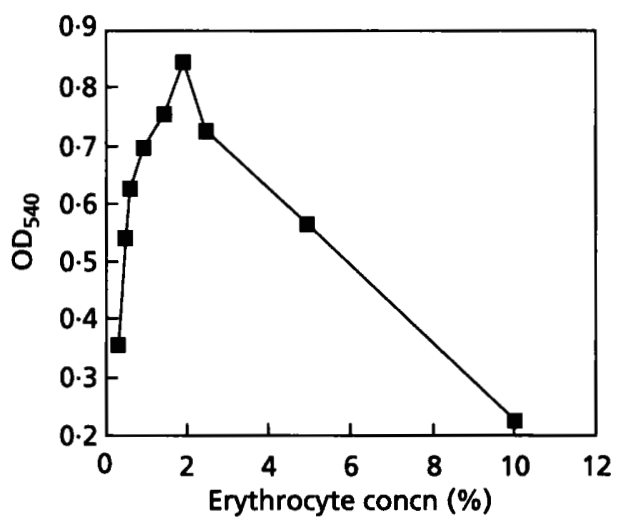

Fig. 3. Effect of erythrocyte concentration on haemolytic activity. Results are expressed as the mean $O D_{540}$ of a 1:32 dilution of the supernatant of $S$. suis capsular type 2, strain S735. The haemolysin was assayed using horse RBC.

Table 1. Effect of different treatments on haemolytic activity of Streptococcus suis capsular type 2 , strain $\mathbf{S 7 3 5}$

The activity of untreated supernatant was $32 \mathrm{HU}$. One $\mathrm{HU}$ is defined as the reciprocal of the haemolysin titre, which was calculated as the highest dilution of the supernatant which caused at least $50 \%$ haemolysis.

\begin{tabular}{|c|c|}
\hline Treatment & $\mathbf{H U}$ \\
\hline \multicolumn{2}{|l|}{ Heating at: } \\
\hline $55^{\circ} \mathrm{C}$ for $60 \mathrm{~min}$ & 16 \\
\hline $58^{\circ} \mathrm{C}$ for $60 \mathrm{~min}$ & 4 \\
\hline $60^{\circ} \mathrm{C}$ for $60 \mathrm{~min}$ & 0 \\
\hline $100^{\circ} \mathrm{C}$ for $30 \mathrm{~min}$ & 0 \\
\hline Proteinase- $\mathrm{K}\left(100 \mu \mathrm{g} \mathrm{ml}^{-1}\right)$ & 0 \\
\hline DTT $(5 \mathrm{mM})$ & 128 \\
\hline Cholesterol (water soluble; $5 \mathrm{mg} \mathrm{ml}^{-1}$ ) & 64 \\
\hline Cholesterol (ethanol soluble; $100 \mu \mathrm{g} \mathrm{ml}^{-1}$ ) & 0 \\
\hline Sodium periodate ( 1 and $5 \mathrm{mM})$ & 4 \\
\hline $\mathrm{CaCl}_{2}(0.01$ and $0.1 \mathrm{M})$ & 32 \\
\hline $\mathrm{MgCl}_{2}(0 \cdot 01$ and $0 \cdot 1 \mathrm{M})$ & 32 \\
\hline $\mathrm{ZnCl}_{2}(0.05$ and $0.10 \mathrm{mM})$ & 32 \\
\hline EGTA $(2.50 \mathrm{mM})$ & 32 \\
\hline Oxygen $\left(100 \mathrm{ml} \mathrm{min}{ }^{-1}\right)$ & 16 \\
\hline
\end{tabular}

at $55^{\circ} \mathrm{C}$ or $58^{\circ} \mathrm{C}$ for $1 \mathrm{~h}$, a partial reduction of haemolytic activity was observed. Haemolytic activity was also completely abolished following the addition of proteinase $\mathrm{K}$. Addition of $\mathrm{CaCl}_{2}, \mathrm{MgCl}_{2}, \mathrm{ZnCl}_{2}$ and EGTA did not influence the activity of $S$. suis capsular type 2 haemolysin. Ethanol-soluble cholesterol $\left(100 \mu \mathrm{g} \mathrm{ml}^{-1}\right)$ completely inhibited haemolytic activity, whereas concentrations of water-soluble cholesterol to $5 \mathrm{mg} \mathrm{ml}^{-1}$ did not have any effect.

Haemolytic activity was significantly increased when the supernatant was incubated with DTT. Treatment of the

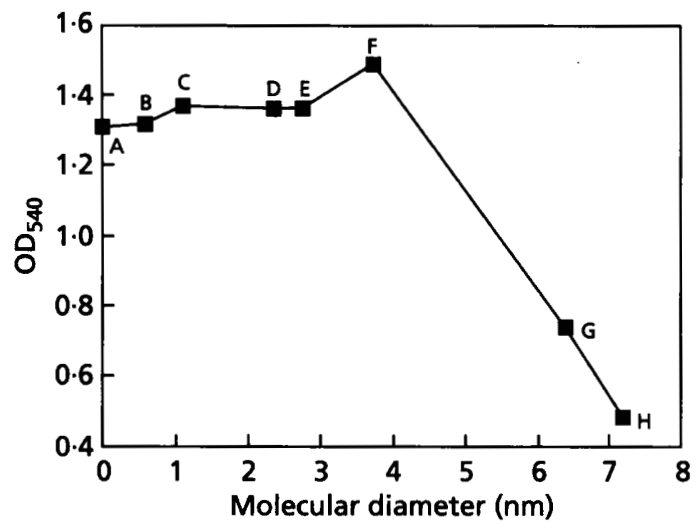

Fig. 4. The inhibitory effects of colloidal protectants on $S$. suis capsular type 2 haemolysin, strain $\$ 735$ (A, none; B, xylose; C, raffinose; D, PEG 1450; E, inulin; F, PEG 3350; G, PEG 8000; H, PEG 10000). Mean $O D_{540}$ corresponds to a $1: 32$ dilution of the supernatant. The haemolysin was assayed using horse RBC.

cell-free supernatant with oxygen reduced haemolytic activity from 32 to $16 \mathrm{HU}$. When this supernatant was treated with DTT, haemolytic activity was totally restored (data not shown). Addition of sodium periodate significantly reduced activity (Table 1 ). Results obtained by modifying the $\mathrm{pH}$ of the solutions showed that maximal activity was present between $\mathrm{pH} 4$ and 8 , with a peak at pH 5. A slight decline was observed below $\mathrm{pH} 4$ and above $\mathrm{pH} 8$.

Finally, the haemolysin shares common epitopes with streptolysin, since a 12800 -fold dilution of antistreptolysin IgG inhibited $50 \%$ of haemolytic activity. In addition, a positive reaction was also obtained with the purified haemolysin by dot-ELISA (results not shown).

\section{Production of haemolysin in vivo}

Most sera from pigs experimentally infected with the reference strain of $S$. suis capsular type 2 did not show a significant anti-haemolysin titre, even after two challenges. Only one animal significantly increased its titre from 3200 to 256002 weeks after the second infection. Interestingly, animals presented a mean titre of 3200 prior to inoculation, which probably means that cholesterol present in normal sera highly inhibited the action of the haemolysin and high dilutions should be used to test anti-haemolytic activity.

\section{Osmotic protection of erythrocytes}

Erythrocytes were suspended in PBS containing various colloid protectants. The inhibitory effects were dependent on the molecular diameter of the colloids. As shown in Fig. 4, most of the protectants used did not prevent haemolysis. However, PEG 8000 and PEG 10000 (molecular diameter of approximately 6.40 and $7.20 \mathrm{~nm}$, respectively) significantly protected the $\mathrm{RBC}$. When the 


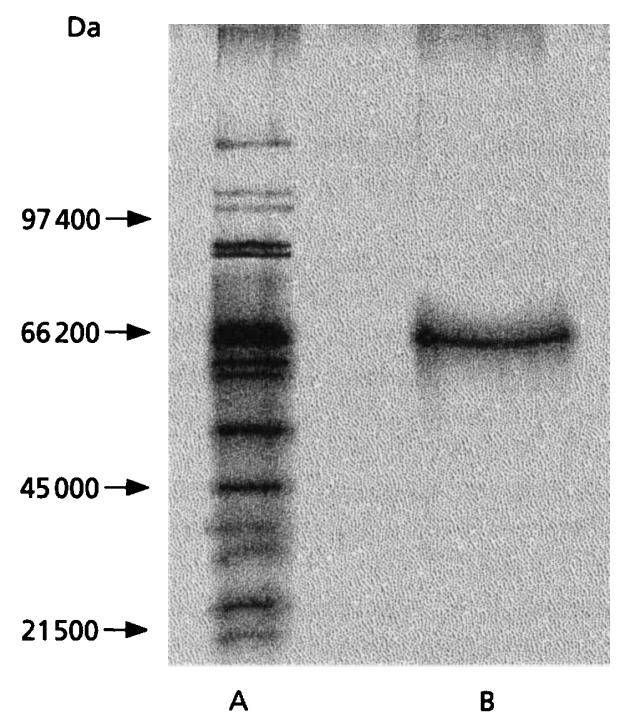

Fig. 5. SDS-PAGE of the crude culture supernatant (lane $A$ ) and a pool of haemolytic fractions after purification using affinity chromatography on a thiopropyl-Sepharose 6B column (lane B). Arrows on the left indicate molecular mass markers in daltons. The gel was stained with silver nitrate.

cells were subsequently washed twice in PEG-containing buffer and resuspended the third time in PBS (without PEG), complete haemolysis occurred immediately. These results indicated that PEG did not primarily inhibit the binding of $S$. suis haemolysin to $\mathrm{RBC}$, but acted as an osmotic protectant by increasing the colloid osmotic pressure in the extracellular milieu.

\section{Purification of the haemolysin}

The ratio of $\mathrm{HU}$ to total protein was significantly higher using the beef and yeast extract diffusate medium than with the THB. However, even in beef and yeast extract diffusate medium numerous protein bands were observed upon SDS-PAGE. After precipitation with ammonium sulfate and ultrafiltration, purification was achieved using the thiopropyl-Sepharose 6B column. This procedure is based on thiol-disulfide exchange chromatography for the selective purification of various thiol proteins. A single protein band at $65 \mathrm{kDa}$ representing the purified haemolysin was observed after affinity chromatography (Fig. 5).

\section{DISCUSSION}

This investigation was initiated by the observation of narrow zones of $\beta$-haemolysis around the colonies of some strains of $S$. suis, especially when cultured on horse blood agar plates. Although $S$. suis, a Lancefield group D Streptococcus, is known as an $\alpha$-haemolytic Streptococcus, several authors previously reported the presence of $\beta$ haemolytic strains as well as a synergistic, CAMP-like haemolytic reaction with staphylococcal $\beta$-lysin (Estoepangestie \& Lämmler, 1993; Hommez et al., 1986).
The results of the present investigation showed that $S$. suis capsular type 2 produced an extracellular haemolysin in THB. The haemolytic activity was higher in stationary cultures than in shaking cultures, probably due to the adverse effect of oxygen.

Most haemolysins possess a first temperatureindependent-step mechanism of action, as revealed by the fact that at $4{ }^{\circ} \mathrm{C}$ no haemolytic activity is observed (Honda \& Miwatani, 1992; Hossain et al., 1993; Shinoda et al., 1985). This does not seem to be the case for $S$. suis haemolysin, since it was active at $4^{\circ} \mathrm{C}$, although a longer lag time was observed. The greatest haemolytic activity was observed at $37^{\circ} \mathrm{C}$, whereas an intermediate activity was observed at $25^{\circ} \mathrm{C}$.

S. suis haemolysin is completely inhibited by free cholesterol, as is the case with other haemolysins (Alouf \& Geoffroy, 1991). Results presented in this study indicated that testing a lipid in aqueous solution for interaction can lead to erroneous results due probably to micellar formation. These erroneous results were also reported for Aeromonas bydrophila haemolysin (Kozaki et al., 1987). The haemolytic differences observed with erythrocytes from different animal species and $S$. suis haemolysin had previously been demonstrated for other haemolysins (Hossain et al., 1993; Kozaki et al., 1987). Bernheimer et al. (1975) reported that the erythrocyte membranes from different animal species contained a variable amount of phosphatidylcholine, which could explain the different susceptibilities.

The haemolysin was significantly activated by DTT. As mentioned by Alouf (1980), the effect of DTT was only observed after a previous increase in $\mathrm{pH}$ (results not shown). As is the case for the streptolysin $\mathrm{O}$, periodate oxidation caused complete and irreversible loss of activity (Alouf, 1980). On the other hand, divalent cations did not affect haemolytic activity, as is the case with other haemolysins (Miyake et al., 1989; Frey \& Nicolet, 1988).

The finding that colloidal compounds such as PEG 8000 and PEG 10000 can inhibit erythrocyte lysis suggests that $S$. suis haemolysin induces osmotic lysis of erythrocytes by forming transmembrane pores of approximately $7 \mathrm{~nm}$ diameter. A similar mechanism has been reported in studies of, for example, Eschericbia coli haemolysin (Bhakdi et al., 1986), staphylococcal toxin (Bhakdi et al., 1984) and streptolysin O (Alouf \& Geoffroy, 1991). In addition, it would seem that a multi-hit lytic system is involved: more than one haemolysin molecule seems to be required to lyse a single erythrocyte since a decrease in haemolysis was obtained by increasing the concentration of erythrocyte suspension (Inoe et al., 1976; Hossain et al., 1993).

The haemolysin of $S$. suis capsular type 2 is a protein of $65 \mathrm{kDa}$, as shown by SDS-PAGE and silver staining. Jacobs et al. (1994) reported that a haemolysin produced by the P1/7 strain had a molecular mass of $54 \mathrm{kDa}$. Data concerning the molecular mass of streptolysin $\mathrm{O}$ also varied considerably, depending on the purificaion method (Alouf, 1980). The haemolysin protein is not the EF or $\mathrm{EF}^{*}$ factor reported by Vecht et al. $(1992,1993)$, since the 
molecular masses of the latter are much higher. In addition, we did not find any correlation between EF, EF* and/or MRP and haemolysin production (unpublished observations).

Finally, the production of haemolysin in vivo, by measuring the production of anti-haemolysin antibodies after an experimental inoculation, was studied in pigs. Even though challenged pigs were extremely ill, most of them did not produce antibodies against the haemolysin. It is possible that the haemolysin is produced in vivo in low quantities in infected pigs and only a weak immunologic reaction is generated.

In conclusion, the haemolysin produced by $S$. suis capsular type 2 belongs to the family of toxins known as thiolactivated toxins or, as more recently named, antigenically related cholesterol-binding cytolytic toxins (Alouf \& Geoffroy, 1991), since it shares common characteristics with other members of this family, such as sensitivity to oxygen and oxidizing agents, activation by reducing agents, inhibition by low concentrations of cholesterol, formation of transmembrane pores and a 'multi-hit' mechanism of action. In addition, anti-streptolysin antibodies inhibited haemolytic activity. To our knowledge, $S$. suis is the only Lancefield group D Streptococcus which produces a haemolysin with these characteristics. The role of this haemolysin in the pathogenesis of $S$. suis infections remains to be investigated.

\section{ACKNOWLEDGEMENTS}

We acknowledge Dr Robert Higgins for reviewing the manuscript. We are also indebted to Annie Beauséjour for technical assistance. This work was supported, in part, by the Ministère de l'Enseignement Supérieur et de la Science.

\section{REFERENCES}

Alouf, J. E. (1980). Streptococcal toxins (streptolysin O, streptolysin S, erythrogenic toxin). Pharmacol Ther 11, 661-717.

Alouf, J. E. \& Geoffroy, C. (1991). The family of the antigenicallyrelated cholesterol-binding ('sulphydryl-activated') cytolytic toxins. In Sourcebook of Bacterial Protein Toxins, pp. 147-186. New York: Academic Press.

Arends, J. P. \& Zanen, H. C. (1988). Meningitis caused by Streptococcus suis in humans. Rev Infect Dis 10, 131-137.

Bernheimer, A. W., Avigad, L. S. \& Avigad, G. (1975). Interactions between aerolysin, erythrocytes and erythrocyte membranes. Infect Immun 11, 1312-1319.

Bhakdi, S., Muhly, M. \& Füssle, R. (1984). Correlation between toxin binding and haemolytic activity in membrane damage by staphylococcal alpha-toxin. Infect Immun 46, 318-323.

Bhakdi, S., Mackman, N., Nicaud, M. \& Holland, I. B. (1986). Escherichia coli hemolysin may damage target cell membranes by generating transmembrane pores. Infect Immun 52, 63-69.

Estoepangestie, S. \& Lämmler, Ch. (1993). Distribution of capsular types 1 to 28 and further characteristics of Streptococcus suis isolates from various European countries. Zentralbl. Bakteriol 279, 394-403.

Frey, J. \& Nicolet, J. (1988). Regulation of hemolysin expression in Actinobacillus pleuropneumoniae serotype 1 by $\mathrm{Ca}^{2+}$. Infect Immun 56, 2570-2575.
Gottschalk, M., Higgins, R., Jacques, M., Mittal, K. \& Henrichsen, J. (1989). Description of 14 new capsular types of Streptococcus suis. J Clin Microbiol 27, 2633-2636.

Gottschalk, M., Petitbois, S., Higgins, R. \& Jacques, M. (1991a). Adherence of Streptococcus suis type 2 to porcine lung sections. Can J Vet Res 55, 302-304.

Gottschalk, M., Higgins, R., Jacques, M., Beaudoin, M. \& Henrichsen, J. (1991b). Characterization of six new capsular types (23 through 28) of Streptococcus suis. J Clin Microbiol 29, 2590-2594.

Gottschalk, M., Higgins, R., Jacques, M. \& Dubreuil, J. D. (1992). Production and characterization of two Streptococcus suis capsular type 2 mutants. Vet Microbiol 30, 59-71.

Higgins, R., Gottschalk, M., Beaudoin, M. \& Rawluk, S. A. (1992). Prevalence of different capsular types of Streptococcus suis in Quebec and Alberta. Can Vet J 33, 27-30.

Hommez, L., Devriese, L. A., Henrichsen, J. \& Castryck, F. (1986). Identification and characterization of Streptococcus suis. Vet Microbiol 11, 349-355.

Honda, T., Ni, Y. \& Miwatani, T. (1992). The thermostable direct hemolysin of Vibrio parabaemolyticus is a pore-forming toxin. Can J Microbiol 38, 1175-1180.

Hossain, A., Stewart-Tull, D. \& Freer, J. H. (1993). Heat-labile and heat-stable haemolysins of Campylobacter jejuni. FEMS Im munol Med Microbiol 6, 331-340.

Inoe, K., Akiyama, Y., Kinoshita, T., Higashi, Y. \& Amano, T. (1976). Evidence for a one-hit theory in the immune bactericidal reaction and demonstration of a multi-hit response for hemolysis by streptolysin $\mathrm{O}$ and Clostridium perfringens theta-toxin. Infect Immun 13, 337-344.

Jacobs, A. A., Loeffen, L., van den Berg, J. \& Storm, P. (1994). Identification of a thiol-activated hemolysin (suilysin) of Streptococcus suis. Infect Immun 62, 1742-1748.

Kozaki, S., Kato, K., Asao, T., Kamata, Y. \& Sakaguchi, G. (1987). Activities of Aeromonas bydrophila hemolysins and their interaction with erythrocyte membranes. Infect Immun 55, 1594-1599.

Laemmli, U. K. (1970). Cleavage of structural proteins during the assembly of the head of bacteriophage T4. Nature 227, 680-685.

Lee, C., Koizumi, K., Henrichsen, J., Perch, B., Lin, C. \& Egan, W. (1984). Capsular polysaccharides of nongroupable streptococci that cross-react with pneumococcal group 19. Infect Immun 133, 2706-2711.

Miyake, M., Honda, T. \& Miwatani, T. (1989). Effects of divalent cations and saccharides on Vibrio meschnikovii cytolysin-induced hemolysis of rabbit erythrocytes. Infect Immun 57, 158-163.

Palmer, D. F. (1981). In $A$ Guide to the Performance of the Standardized Diagnostic Complement Fixation Method and Adaptation to Microtest, pp. 5A-11A. Atlanta: US Department of Health and Human Services, Center for Disease Control.

Quessy, S., Dubreuil, J. D., Caya, M. \& Higgins, R. (1993). Active immunization of mice against Streptococcus suis serotype 2 infections. Conference of Research Workers in Animal Diseases, Chicago 74, 9.

Quessy, S., Dubreuil, J. D., Jacques, M., Malouin, F. \& Higgins, R. (1994). Increase of capsular material thickness following in vivo growth of virulent Streptococcus suis serotype 2 strains. FEMS Microbiol Lett 115, 19-26.

Scherrer, R. \& Gerhardt, P. (1971). Molecular sieving by the Bacillus megaterium cell wall and protoplast. $J$ Bacteriol 107, 718-735.

Shinoda, S., Miyoshi, S., Yamanaka, H. \& Miyoshi-Nakahara, N. (1985). Some properties of Vibrio vulnificus hemolysin. Microbiol Immunol 29, 583-590.

Tapsall, J.W. \& Phillips, E. A. (1991). Relationship between 
pigment production and haemolytic formation by Lancefield group B streptococci. Pathology 23, 139-144.

Vecht, U., Wisselink, H. J., van Dijk, J. E. \& Smith, H. E. (1992). Virulence of Streptococcus suis type 2 strains in newborn germfree pigs depends on phenotype. Infect Immun 60, 550-556.

Vecht, U., Wisselink, H. J., Anakotta, J. \& Smith, H. E. (1993).
Discrimination between virulent and non-virulent Streptococcus suis type 2 strains by enzyme-linked immunosorbent assay. Vet Microbiol $34,71-82$.

Received 10 August 1994; accepted 1 September 1994. 